Journal of Engineering and Applied Sciences 15 (1): 220-226, 2020

ISSN: 1816-949X

(C) Medwell Journals, 2020

\title{
Efficiency Improvement of a Gas Chromatographic-Mass Spectrometric Method for Quantification of Nicotine in Hookah (Water Pipe) Tobacco Products
}

\author{
Hazim M. Ali \\ Department of Chemistry, College of Science, Jouf University, \\ P.O. Box 2014, Sakaka, Aljouf, Saudi Arabia
}

\begin{abstract}
In the present study, a highly sensitive Gas Chromatographic-Mass Spectrometric (GC-MS) method and single-step extraction procedure have been developed for the determination of nicotine level in Hookah tobacco products samples. The principle focus of the developed method is the lower limit of detection (0.025 $\left.\mathrm{ng} \mathrm{mL}^{-1}\right)$ and a wide linear range (0.03-17000 $\mathrm{ng} \mathrm{mL}^{-1}$ ) achieved that can have important implications in the determination of nicotine in any investigated samples. In addition, the accuracy and precision values of the method were in the range of $98.07-103.81$ and $0.2660-1.7712 \%$, respectively. While the extraction recovery of nicotine, when spiked to hookah tobacco products was ranged from 94.85-98.00\%. The present chromatographic method showed higher sensitivity, linearity precision and accuracy, when compared with the reported chromatographic methods. Finally, the hookah tobacco products samples were used to evaluate the method applicability for the determination of nicotine.
\end{abstract}

Key words: Hookah tobacco products, nicotine, methyl nicotinate, single-step extraction procedure, sensitivity, recovery

\section{INTRODUCTION}

Nicotine is chemically designated as 3-[(2S)-1-methylpyrrolidin-2-yl]pyridine (Fig. 1) and it is the main alkaloid found in tobacco leaves (Nicotianatabacum L., Solanaceae) (Levent et al., 2009). Nicotine is widely consumed in two patterns, tobacco products in the form of cigarettes, cigars or Hookah (waterpipe) and anti-smoking pharmaceuticals such as dermal patches, tablets, chewing gum and nasal sprays (Magni et al., 2016; Marclay and Saugy, 2010; Svorc et al., 2014). Tobacco nicotine increases stimulation and pleasure and decreases stress and anxiety because of its effects on the neurotransmitter release (dopamine and others) in brain tissue (Benowitz, 2008; Zuo et al., 2004). On the other hand, nicotine has predominant effects on smokers and non-smokers health such as enhancement blood sugar release, blood pleasure and increase heart pulse rate because it is absorbed through the skin, mucous membranes in the mouth and nose or by the lungs during smoke inhalation (Miller et al., 2010; Shrivas and Patel, 2010). Tobacco smoking is still the commonly preferred path for intake of nicotine in spite of the fact that it often causes cancer of various organs involving lung, stomach, bladder, colon, kidney, nose and oral cavity (Banerjee et al., 2013; Yu and Chang, 2013) and also the difficulties that meet the smokers to quitting the smoking habit (Svorc et al., 2014). (a)<smiles>CN1CCC[C@H]1c1cccnc1</smiles><smiles>COC(=O)c1cccnc1</smiles>

Fig. 1: (a) Chemical structures of nicotine and (b) Methyl nicotinate, IS

In recent years, hookah, also known as a waterpipe, sheesha, chicha, gozah and narghile, smoking is gaining popularity nationwide, especially among urban youth, college students and young professionals (Hadidi and Mohammed, 2004; Ward et al., 2007). Hookah tobacco pastes are divided into two main types according to its constituents, known as moassel and jurak. It generally contains tobacco leaves, molasses (black honey or juice of sugarcane), with the addition of glycerin and fruits flavor in case of moassel while in case of jurak, spices, dried fruits and tar are presents (El-Hakim and Uthman, 1999; Farid, 2013). Hookah tobacco smoking is a form of tobacco consumption that utilizes a single or multi-stemmed instrument to smoke flavored or non-flavored tobacco, where tobacco smoke passes through water or another liquid container before reaching the smoker (Auf et al., 2012).

Various analytical techniques, spectrophotometry (Al-Tamrah, 1999; Asthana et al., 2004), spectrofluorimetry (Zhou et al., 2009), capillary electrophoresis (Ralapati, 1997; Yang and 
Smetena, 1995), voltammetry (Levent et al., 2009; Svorc et al., 2014), liquid chromatography (Abdallah et al., 2016; Dash and Wong, 1996; Miller et al., 2010; Tambwekar et al., 2003; Yasuda et al., 2013) and gas chromatography (Hossain and Salehuddin, 2013; Kim et al., 2005; Magni et al., 2016; Man et al., 2006; Nystrom et al., 1997; Siegmund et al., 1999) have been used for the detection of nicotine in different matrices (e.g., tobacco product, anti-smoking pharmaceutical products and biological fluids). There are only one published method describing the determination of nicotine content in hookah tobacco products (Hadidi and Mohammed, 2004). This method applied only for flavored and unflavored moassel tobacco samples commercial available in Jordan market and multi-step extraction procedure used for gas chromatography provided with nitrogen phosphorous detector for analysis of nicotine.

The aim of the present study is to develop a simple and fast method based on gas chromatography-mass spectrometry (GC-MS) with highly sensitivity and suitable linearity for the determination of nicotine in flavored, unflavored moassel tobacco and jurak samples. In addition, the method in the present work should characterized by its low cost, simple extraction procedure and minimizing the interference effects.

\section{MATERIALS AND METHODS}

Chemicals and materials: Nicotine was obtained from Loba Chemie Co., India. Methyl nicotinate (internal standard), HPLC Methanol and anhydrous sodium sulphate were purchased from Sigma-Aldrich (Spruce street, St. Luis, USA).

Standard and calibration solutions: Standard stock solutions containing $100 \mu \mathrm{g} \mathrm{mL}^{-1}$ of the nicotine and methyl nicotinate (Internal Standard, IS) were prepared daily in methanol. A set of eighteen-calibration solution made up of $0.03,0.05,0.1,0.5,1,5,10,50,100,300$, 500, 1000, 3000, 5000, 7000, 10000, 13000 and $17000 \mathrm{ng} \mathrm{mL}^{-1}$ nicotine was prepared from stock solution. Subsequently, the methyl nicotinate (IS) was added to each calibration solution to maintain a concentration of $500 \mathrm{ng} \mathrm{mL} \mathrm{m}^{-1}$ and the mixture was diluted with methanol. Three working solutions (25, 400 and $1000 \mathrm{ng} \mathrm{mL}^{-1}$ ) were used toevaluating the accuracy and precision of the developed method. Extraction recovery was performed by spiking hookah tobacco sample with three different concentration levels (85, 550 and $2000 \mathrm{ng} \mathrm{mL}^{-1}$ ) of nicotine and with the IS at a fixed amount (500 $\mathrm{ng} \mathrm{mL}^{-1}$ ). All solutions were stored at $4{ }^{\circ} \mathrm{C}$ prior to analysis.
GC-MS instrumentation and conditions: Analysis of hookah tobacco samples was carried out by gas chromatography (TRACE ${ }^{\mathrm{TM}} 1310$ GC) provided with Single Quadrupole Mass Spectrometer (ISQLT) and AI/AS1310 auto-sampler unit (Thermo Scientific, USA). Separation of nicotine was done by TG-5MS column ( $60 \mathrm{~m}, 0.25 \mathrm{~mm}$ I.D., $0.25 \mu \mathrm{m}$ film thickness, Thermo Scientific, USA) with $1 \mathrm{~mL} \mathrm{~min}{ }^{-1}$ helium (carrier gas) flow rate. The applied temperature program was started at $80^{\circ} \mathrm{C}$ for $3 \mathrm{~min}$, then rising to $250^{\circ} \mathrm{C}$ ( 5 min hold) at a rate of $30^{\circ} \mathrm{C} \mathrm{min}^{-1}$. The temperatures of the injector, transfer lineand ion source were adjusted to 250, 250 and $255^{\circ} \mathrm{C}$, respectively. The analysis was performed in Selected Ion Monitoring (SIM) mode using electron ionization with $70 \mathrm{eV}$ energy. The characteristic ions of nicotine and methyl nicotinate (internal standard) were used for identification: $\mathrm{m} / \mathrm{z} 42,84,133,162$ and 51; $\mathrm{m} / \mathrm{z}$ 87, 106 and 137, respectively. The split-less mode of the injector was used with an injection volume of $1 \mu \mathrm{L}$. Data processing and analysis data were carried out using Xcalibur Program Version 3.1 (Thermo Scientific, USA).

Sample collection and preparation: Twenty-five hookah tobacco products samples were purchased from tobacco product shops. The hookah tobacco products samples were divided into the following groups by fruit-flavored Almoassel tobacco (sixteen samples; $\mathrm{F}_{1}-\mathrm{F}_{16}$ ), unflavored Almoassel tobacco (Four samples; $\mathrm{A}_{1}-\mathrm{A}_{4}$ ) and Jurak (Five samples; $\mathrm{J}_{1}-\mathrm{J}_{5}$ ) as shown in Table 1.

The $1 \mathrm{~g}$ of hookah tobacco was weighed into a roundbottom flask, equipped with a stirring bar, methyl nicotinate (internal standard, $500 \mathrm{ng} \mathrm{mL}^{-1}$ in extracting solvent; $50 \mathrm{~mL}$ ) was added and completed the volume to $50 \mathrm{~mL}$ with methanol. The flask was connected to a reflux condenser and the mixture was stirred and directly heated on stirrer-hotplate adjusted to $350 \mathrm{rpm}$ and $65^{\circ} \mathrm{C}$ for $30 \mathrm{~min}$. The mixture was left to cool at room temperature and then filtrated. To remove water, anhydrous sodium sulfate was added to the filtrate. Then, the filtrate was further filtered by passing through a $0.2 \mu \mathrm{m}$ CHROMAFIL ${ }^{\circledR} \mathrm{X}$ tra PTFE syringe filter (MACHEREY-NAGEL GmbH and Co.KG, Düren, Germany) directly to GC vials and $1 \mu \mathrm{L}$ of the filtrate was used for the analysis.

Method validation: The linearity, Limit of Detection (LOD), Limit of Quantitation (LOQ), accuracy and precision, specificity and extraction recovery of developed method was evaluated according to the US Food and Drug Administration (USFDA) guidelines for the bioanalytical method. 
J. Eng. Applied Sci., 15 (1): 220-226, 2020

Table 1: Amounts of nicotine in hookah tobacco products

\begin{tabular}{|c|c|c|c|c|c|}
\hline Sample types & $\begin{array}{c}\begin{array}{c}\text { Sample } \\
\text { codes }\end{array} \\
\end{array}$ & Brands & Flavored types & Manufactured country & $\begin{array}{c}\begin{array}{c}\text { Concentration } \\
(\mathrm{mg} / \mathrm{g}) \pm \mathrm{SD}^{\mathrm{a}}\end{array} \\
\end{array}$ \\
\hline \multirow{16}{*}{$\begin{array}{l}\text { Fruit flavored } \\
\text { almoassel tobacco }\end{array}$} & $\mathrm{F}_{1}$ & AL Fakher & Orange & United Arab Emirates & $1.577 \pm 0.040$ \\
\hline & $\mathrm{F}_{2}$ & & Grape with Berry & & $1.044 \pm 0.027$ \\
\hline & $\mathrm{F}_{3}$ & & Lemon with Mint & & $1.200 \pm 0.021$ \\
\hline & $\mathrm{F}_{4}$ & & Vanilla & & $1.338 \pm 0.013$ \\
\hline & $\mathrm{F}_{5}$ & & Mint & & $1.300 \pm 0.044$ \\
\hline & $\mathrm{F}_{6}$ & Mazaya & Natural Two Apples & Jordan & $0.973 \pm 0.013$ \\
\hline & $\mathrm{F}_{7}$ & & Watermelon with Mint & & $0.594 \pm 0.014$ \\
\hline & $\mathrm{F}_{8}$ & & Mastic Gum & & $0.633 \pm 0.002$ \\
\hline & $\mathrm{F}_{9}$ & & Blueberry Exotica & & $0.560 \pm 0.014$ \\
\hline & $\mathrm{F}_{10}$ & & Heavenly Fruit & & $0.553 \pm 0.011$ \\
\hline & $F_{11}$ & & Gum with cinnamon & & $0.489 \pm 0.003$ \\
\hline & $\mathrm{F}_{12}$ & $\mathrm{~J}$ and $\mathrm{J}$ (Al-Bazz) & Mint & Egypt & $0.516 \pm 0.009$ \\
\hline & $\mathrm{F}_{13}$ & & Strawberry & & $0.378 \pm 0.001$ \\
\hline & $\mathrm{F}_{14}$ & & Lemon with Mint & & $0.518 \pm 0.007$ \\
\hline & $\mathrm{F}_{15}$ & & Two Apples & & $0.620 \pm 0.018$ \\
\hline & $\mathrm{F}_{16}$ & & Grape with Mint & & $0.515 \pm 0.015$ \\
\hline \multirow{4}{*}{$\begin{array}{l}\text { Unflavored } \\
\text { almoassel tobacco }\end{array}$} & $\mathrm{A}_{1}$ & Al-Bazz & Without & Egypt & $1.625 \pm 0.051$ \\
\hline & $\mathrm{A}_{2}$ & Alborg & & Egypt & $2.979 \pm 0.073$ \\
\hline & $\mathrm{A}_{3}$ & Zaghloul & & Egypt & $2.723 \pm 0.033$ \\
\hline & $\mathrm{A}_{4}$ & Zawati Elnaama & & Egypt & $2.815 \pm 0.006$ \\
\hline \multirow[t]{5}{*}{ Jurak } & $\mathrm{J}_{1}$ & Al-Safi & Without & India & $0.786 \pm 0.007$ \\
\hline & $\mathrm{J}_{2}$ & Abou Dallah & & India & $0.850 \pm 0.006$ \\
\hline & $\mathrm{J}_{3}$ & Sheesha & & India & $0.779 \pm 0.005$ \\
\hline & $\mathrm{J}_{4}$ & Dallah (Alasly) & & India & $0.648 \pm 0.002$ \\
\hline & $\mathrm{J}_{5}$ & Alasly Baeshen & & India & $1.069 \pm 0.005$ \\
\hline
\end{tabular}

\section{RESULTS AND DISCUSSION}

Optimization of sample extraction conditions: Single-step extraction procedure was used for extraction of nicotine from hookah tobacco products samples in presence of methanol as a suitable solvent for the extraction process. Several parameters, including temperature and time, may have an effect on the efficiency of the nicotine extraction. In order to optimize the hookah tobacco samples extraction, different temperatures $\left(30,40,50,60,65,70\right.$ and $\left.70^{\circ} \mathrm{C}\right)$ and different extraction times $(5,10,20,30,40,50$ and $60 \mathrm{~min}$ ) were tested in this study. Finally, $65^{\circ} \mathrm{C}$ and 30 min were chosen as an optimal exposure temperature and time for the extraction of nicotine from different hookah tobacco samples.

Method development: Column type and oven temperature were tested to optimize the chromatographic separation of nicotine and methyl nicotinate (IS). Two different type of capillary column, TG-5MS column (60 m, $0.25 \mathrm{~mm}$ I.D., $0.25 \mu \mathrm{m}$ film thickness) and $\mathrm{Rxi}^{\circledR}$-624Sil MS column (60 m, $0.53 \mathrm{~mm}$ I.D., $3.0 \mu \mathrm{m}$ thickness) were used to check the best separation of nicotine and methyl nicotinate. The TG-5MS column was considered the most suitable column for the separation and quantification of nicotine and methyl nicotinate due to its high selectivity for nicotine determination with no interferences from other hookah tobacco sample constituents as shown in Fig. 2 and 3.
Oven temperature and holding time are important factors in enhancing both the separation speed and efficiency of the analyte. The nicotine peak responses were determined when starting oven temperature were set at $40,50,60,70,80,90$ and $100^{\circ} \mathrm{C}$ and hold for $1,2,3,4$ and $5 \mathrm{~min}$, the results showed $80^{\circ} \mathrm{C}$ was the optimal equilibration temperature and 3 min was the suitable holding time. The final oven temperature, temperature-increasing rate and holding time were also tested. The results indicated $250^{\circ} \mathrm{C}, 30^{\circ} \mathrm{C} \mathrm{min}{ }^{-1}$ and 5 min were the suitable conditions for the final oven temperature, temperature-increasing rate and holding time respectively. Finally, the suitable oven temperature was therefore, set at $80^{\circ} \mathrm{C}$ for $3 \mathrm{~min}$, then rising to $250^{\circ} \mathrm{C}$ (5 min hold) at a rate of $30^{\circ} \mathrm{C} \mathrm{min}{ }^{-1}$.

Under the chromatographic conditions described above, the separation of nicotine in pure form and hookah tobacco products samples was achieved within $13.67 \mathrm{~min}$ at TG-5MS column as shown in Fig. 2 and 3, respectively. The GC retention times were consistent at $8.71 \mathrm{~min}$ and $10.11 \mathrm{~min}$ for nicotine and methyl nicotinate (IS), respectively.

\section{Validation of the method}

Specificity: Specificity was confirmed by analyzing the chromatograms of nicotine standard solution and hookah tobacco products samples in presence of methyl nicotinate as an Internal Standard (IS). The results showed that the developed method was specific for the detection of nicotine as there was no other peak to interfere with the peak of nicotine as shown in Fig. 3. 


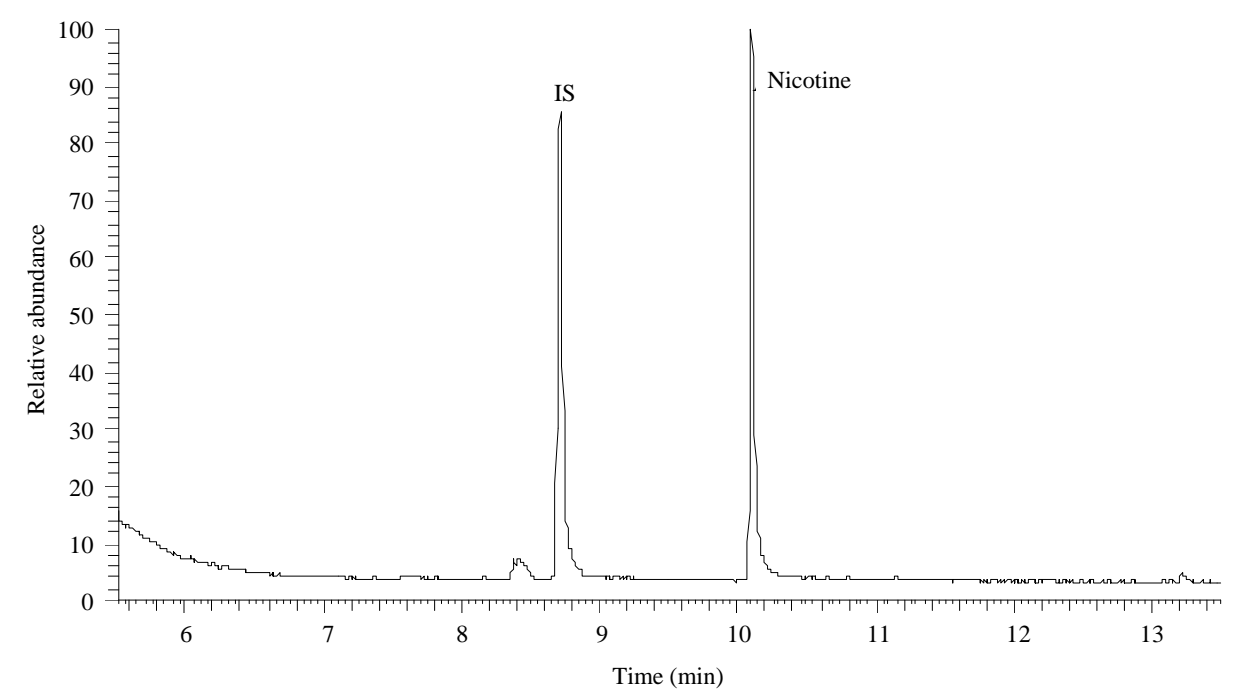

Fig. 2: Chromatogram of nicotine and methyl nicotinate (IS) in pure form

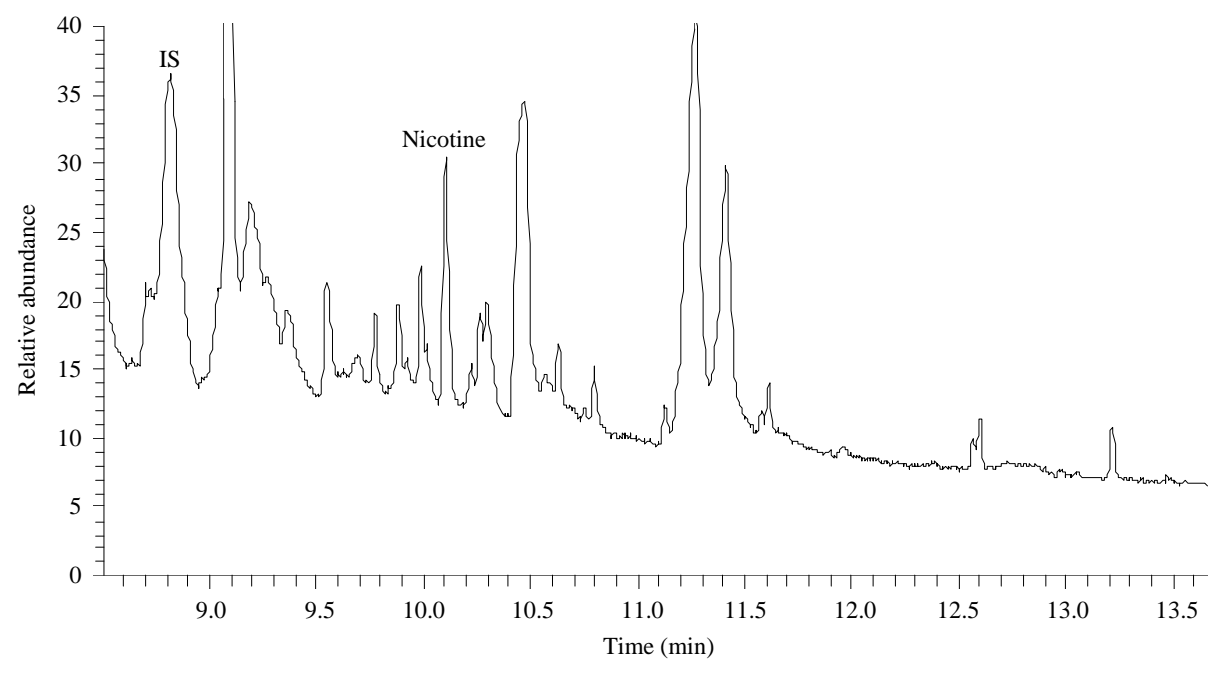

Fig. 3: Chromatogram of nicotine and methyl nicotinate (IS) in sample $F_{13}$ of fruit-flavored almoassel tobacco

Linearity, limit of detection and limit of quantification: The calibration curve of nicotine was constructed by plotting peak area of nicotine versus concentration at eighteen concentration levels. Limit of Detection (LOD) and Limit of Quantitation (LOQ) of nicotine was calculated using the following formulas:

$$
3 \times \mathrm{SD} / \mathrm{S}
$$

and:

$$
10 \times \mathrm{SD} / \mathrm{S}
$$

where, SD is the Standard Deviation of intercept and $\mathrm{S}$ is the slope of calibration curve), respectively. Calibration was linear in the concentration ranged from $0.03-17000 \mathrm{ng} \mathrm{mL}^{-1}$. The linear regression equation was:

$$
\mathrm{Y}=4 \times 10^{7} \times-732025(\mathrm{n}=3)
$$

with the correlation coefficient was 0.999. The LOD and the LOQ for nicotine under GC conditions were 0.025 and $0.083 \mathrm{ng} \mathrm{mL}^{-1}$, respectively.

Precision and accuracy: The precision and accuracy were determined as the percentage relative standard deviation:

$$
\mathrm{RSD}=\frac{\mathrm{SD}}{\text { Mean measured value }} \times 100
$$

and the percentage recovery:

$$
\text { Recovery }(\%)=\frac{\text { Measured value }}{\text { Added value }} \times 100
$$


J. Eng. Applied Sci., 15 (1): 220-226, 2020

Table 2: Accuracy and precision of the proposed method for the analysis of nicotine

\begin{tabular}{|c|c|c|c|c|c|c|}
\hline \multirow[b]{2}{*}{$\begin{array}{l}\text { Concentration } \\
\left.\text { added (ng mL }{ }^{-1}\right)\end{array}$} & \multicolumn{3}{|l|}{ Intra-day } & \multicolumn{3}{|l|}{ Inter-day } \\
\hline & $\begin{array}{l}\text { Concentration found } \\
\left(\text { (ng mL }{ }^{-1}\right) \pm \mathrm{SD}^{\mathrm{a}}\end{array}$ & Recovery (\%) & RSD (\%) & $\begin{array}{l}\text { Concentration found } \\
\left.\text { (ng mL }{ }^{-1}\right) \pm S D\end{array}$ & Recovery (\%) & RSD (\%) \\
\hline 25 & $24.9 \pm 0.2$ & 99.76 & 0.8855 & $24.5 \pm 0.4$ & 98.07 & 1.7712 \\
\hline 400 & $405.5 \pm 1.1$ & 101.38 & 0.2660 & $398.2 \pm 3.6$ & 99.54 & 0.9039 \\
\hline 1000 & $1038.1 \pm 3.1$ & 103.81 & 0.2965 & $1031.2 \pm 8.3$ & 103.12 & 0.8015 \\
\hline
\end{tabular}

Table 3: Recovery analysis of nicotine in Hookah tobacco products using developed method

\begin{tabular}{lcrrrr}
\hline Tobacco samples & Determined $\left(\mathrm{ng} \mathrm{mL}^{-1}\right)$ & Added $\left(\mathrm{ng} \mathrm{mL}^{-1}\right)$ & Expected $\left(\mathrm{ng} \mathrm{mL}^{-1}\right)$ & Found $\left(\mathrm{Mean} \pm \mathrm{SD}, \mathrm{ng} \mathrm{mL}^{-1}\right)$ & Recovery $(\%)$ \\
\hline $\mathrm{A}_{4}$ & 2252 & 85 & 2337 & $83 \pm 4$ & 97.64 \\
& & 550 & 2802 & $535 \pm 7$ & 97.27 \\
& & 2000 & 4252 & $1944 \pm 64$ & 97.20 \\
$\mathrm{~J}_{5}$ & 85 & 550 & 940 & $83 \pm 5$ & 97.64 \\
& & 2000 & 2855 & $539 \pm 2$ & 98.00 \\
& & & & $1897 \pm 29$ & 94.85 \\
\hline
\end{tabular}

Table 4: Comparison of the proposed method with some reported methods

\begin{tabular}{lccc}
\hline Methods & Linear range $\left(\mathrm{ng} \mathrm{mL}^{-1}\right)$ & Limit of detection $\left(\mathrm{ng} \mathrm{mL}^{-1}\right)$ & References \\
\hline HPLC-UV method & $50-5000$ & 6.600 & 24 \\
HPLC-FLD method & $0.3-1000$ & 0.090 & 25 \\
LC-MS/MS method & $0.26-52.5$ & 0.086 & 21 \\
LC-ESI-MS/MS & $10-10000$ & 0.500 & 2 \\
GC-NPD method & $2-125$ & 0.500 & 30 \\
GC-MS method & $0.5-5000$ & 0.200 & 28 \\
The developed method & $0.03-17000$ & 0.025 & This work \\
\hline
\end{tabular}

Three different concentration levels (25, 400 and $1000 \mathrm{ng} \mathrm{mL}{ }^{-1}$ ) were used for evaluating the intraday and inter-day precision and accuracy of the developed method. The intra-day and inter-day precision were in the range of $0.2660-0.8855$ and $0.8015-1.7712 \%$, respectively as shown in Table 2 . While the intra-day and inter-day accuracy in the range of 99.76-103.81 and 98.07-103.12\%, respectively as denoted in Table 2. The results suggested that the method was reliable, reproducible and accurate.

Recovery: The efficiency of the extraction method was determined based on the recovery:

$$
\text { Recovery }(\%)=\frac{\text { Measured value }}{\text { Added value }} \times 100
$$

and estimated by addition of nicotine in three different concentration levels $\left(85,550\right.$ and $2000 \mathrm{ng} \mathrm{mL}^{-1}$ ) to hookah tobacco products samples in three replicates. The extraction recoveries of spiked nicotine ranged from 94.85-98.00\% as shown in Table 3. The results indicated that the extraction method is precise and reproducible.

Application to hookah tobacco products samples: The developed method was successfully applied for the determination of nicotine content in hookah tobacco products samples. Figure 3 represents the chromatogram of nicotine and methyl nicotinate (IS) in sample $F_{13}$ of fruit-flavored Almoassel tobacco. The content of nicotine in hookah tobacco products samples was reported in Table 1 . The amount of nicotine was found in the range of $0.378-1.577,1.625-2.979$ and $0.648-1.069 \mathrm{mg} \mathrm{g}^{-1}$ in Fruit Flavored Almoassel Tobacco, Unflavored almoassel Tobacco and Jurak, respectively. The amount of nicotine in unflavored Almoassel tobacco samples is higher than other hookah tobacco products samples. That may be due to the number of additives and the amount of additives in unflavored almoassel tobacco samples is less than other hookah tobacco products samples.

Comparison with other chromatographic methods: A comparison of the analytical data of the developed method with other reported chromatographic methods (High-Performance Liquid Chromatography-UV detector (HPLC-UV), High-Performance Liquid Chromatography-Fluorescence Detector (HPLC-FLD), Liquid Chromatography-Mass Spectrometry (LC-MS), liquid Chromatography-Electrospray Ionization-tandem Mass Spectrometry (LC-ESI-MS/MS), Gas Chromatography-Nitrogen-Phosphorus Detector (GCNPD) and Gas Chromatography-Mass Spectrometry (GC-MS) for the determination of nicotine as denoted in Table 4. This method offers a wide linear range and high sensitivity with the lowest limit of detection of $0.025 \mathrm{ng} \mathrm{mL} \mathrm{m}^{-1}$. Up to date, this developed method was found to be the most sensitive chromatographic methods for the determination of nicotine. The high sensitivity makes this method more qualified for the determination of nicotine in any investigated samples. 


\section{CONCLUSION}

A simple, rapid and highly sensitive GC-MS method for determination of nicotine presented in hookah tobacco products has been developed and validated. The GC-MS analysis of nicotine was carried out in $13.67 \mathrm{~min}$ with no interference from hookah tobacco products constituents and additives. The amount of nicotine was found in the range of $0.378-1.577,1.625-2.979$ and $0.648-1.069 \mathrm{mg} \mathrm{g}^{-1}$ in Fruit Flavored Almoassel Tobacco, unflavored almoassel tobacco and Jurak, respectively. The amount of nicotine in unflavored Almoassel tobacco samples is higher than other hookah tobacco products samples. The GC-MS method exhibited a good linearity, precision, accuracy and extraction recovery. This method was successfully applied to the determination of nicotine content in hookah tobacco products with satisfactory results and recommended to be applied in any investigated samples.

\section{ACKNOWLEDGEMENTS}

The researcher would like to express their sincere gratitude to Prof. Dr. Ahmed El-Ghorab, professor of natural products, Chemistry Department, College of Science, Jouf University, Aljouf, Saudi Arabia for his valuable assistance in extraction method of nicotine. The researcher would like to extend his thankful to $\mathrm{Mr}$. Tawfik A. N. Al-Gwlany for his help to collect the hookah tobacco samples.

\section{REFERENCES}

Abdallah, I.A., D.C. Hammell, A.L. Stinchcomb and H.E. Hassan, 2016. A fully validated LC-MS/MS method for simultaneous determination of nicotine and its metabolite cotinine in human serum and its application to a pharmacokinetic study after using nicotine transdermal delivery systems with standard heat application in adult smokers. J. Chromatogr. B., 1020: 67-77.

Al-Tamrah, S.A., 1999. Spectrophotometric determination of nicotine. Anal. Chimica Acta, 379: 75-80.

Asthana, A., R. Rastogi, G. Sunita and V.K. Gupta, 2004. A simple spectrophotometric method for the determination of nicotine in environmental samples. J. Chin. Chem. Soc., 51: 949-953.

Auf, R.A., G.N. Radwan, C.A. Loffredo, M. El Setouhy and E. Israel et al., 2012. Assessment of tobacco dependence in waterpipe smokers in Egypt. Intl. J. Tuberculosis Lung Dis., 16: 132-137.

Banerjee, J., H.A. Al-Wadei and H.M. Schuller, 2013. Chronic nicotine inhibits the therapeutic effects of gemcitabine on pancreatic cancer in vitro and in mouse xenografts. Eur. J. Cancer, 49: 1152-1158.
Benowitz, N.L., 2008. Neurobiology of nicotine addiction: Implications for smoking cessation treatment. Am. J. Med., 121: S3-S10.

Dash, A.K. and S.T. Wong, 1996. Liquid chromatographic method for the determination of nicotine in pharmaceutical formulations. J. Chromatogr. A., 749: 81-85.

El-Hakim, I.E. and M.A. Uthman, 1999. Squamous cell carcinoma and keratoacanthoma of the lower lip associated with goza and shisha smoking. Int. J. Dermatol., 38: 108-110.

Farid, S.M., 2013. Enhancement of radon exposure in narghile (water pipe) smoking areas. Med. J. Islamic World Acad. Sci., 21: 155-162.

Hadidi, K.A. and F.I. Mohammed, 2004. Nicotine content in tobacco used in hubble-bubble smoking. Saudi Med. J., 25: 912-917.

Hossain, A.M. and S.M. Salehuddin, 2013. Analytical determination of nicotine in tobacco leaves by gas chromatography-mass spectrometry. Arabian J. Chem., 6: 275-278.

Kim, I., W.D. Darwin and M.A. Huestis, 2005. Simultaneous determination of nicotine, cotinine, norcotinine and trans-3-hydroxycotinine in human oral fluid using solid phase extraction and gas chromatography-mass spectrometry. J. Chromatogr. B., 814: 233-240.

Levent, A., Y. Yardim and Z. Senturk, 2009. Voltammetric behavior of nicotine at pencil graphite electrode and its enhancement determination in the presence of anionic surfactant. Electrochim. Acta, 55: 190-195.

Magni, P.A., M. Pazzi, M. Vincenti, E. Alladio and M. Brandimarte et al., 2016. Development and validation of a GC-MS method for nicotine detection in Calliphora vomitoria (L.) (Diptera: Calliphoridae). Forensic Sci. Intl., 261: 53-60.

Man, C.N., L.H. Gam, S. Ismail, R. Lajis and R. Awang, 2006. Simple, rapid and sensitive assay method for simultaneous quantification of urinary nicotine and cotinine using gas chromatography-mass spectrometry. J. Chromatogr. B, 844: 322-327.

Marclay, F. and M. Saugy, 2010. Determination of nicotine and nicotine metabolites in urine by hydrophilic interaction chromatography-tandem mass spectrometry: Potential use of smokeless tobacco products by ice hockey players. J. Chromatogr. A., 1217: 7528-7538.

Miller, E.I., H.R.K. Norris, D.E. Rollins, S.T. Tiffany and D.G. Wilkins, 2010. A novel validated procedure for the determination of nicotine, eight nicotine metabolites and two minor tobacco alkaloids in human plasma or urine by solid-phase extraction coupled with liquid chromatography-electrospray ionization-tandem mass spectrometry. J. Chromatogr. B, 878: 725-737. 
Nystrom, L., M. Pettersson and C. Rangemark, 1997. Simple and sensitive method for determination of nicotine in plasma by gas chromatography. J. Chromatogr. B. Biomed. Sci. Appl., 701: 124-128.

Ralapati, S., 1997. Capillary electrophoresis as an analytical tool for monitoring nicotine in ATF regulated tobacco products. J. Chromatogr. B. Biomed. Sci. Appl., 695: 117-129.

Shrivas, K. and D.K. Patel, 2010. Liquid-phase microextraction combined with gas chromatography mass spectrometry for rapid determination of nicotine in one-drop of nightshades vegetables and commercial food products. Food Chem., 122: 314-318.

Siegmund, B., E. Leitner and W. Pfannhauser, 1999. Development of a simple sample preparation technique for gas chromatographic-mass spectrometric determination of nicotine in edible nightshades (solanaceae). J. Chromatogr. A., 840: 249-260.

Svorc, L., D.M. Stankovic and K. Kalcher, 2014. Boron-doped diamond electrochemical sensor for sensitive determination of nicotine in tobacco products and anti-smoking pharmaceuticals. Diamond Relat. Mater., 42: 1-7.

Tambwekar, K.R., R.B. Kakariya and S. Garg, 2003. A validated high performance liquid chromatographic method for analysis of nicotine in pure form and from formulations. J. Pharm. Biomed. Anal., 32: 441-450.
Ward, K.D., T. Eissenberg, J.N. Gray, V. Srinivas and N. Wilson et al., 2007. Characteristics of US waterpipe users: A preliminary report. Nicotine Tob. Res., 9: 1339-1346.

Yang, S.S. and I. Smetena, 1995. Evaluation of capillary electrophoresis for the analysis of nicotine and selected minor alkaloids from tobacco. Chromatographia, 40: 375-378.

Yasuda, M., T. Ota, A. Morikawa, K.I. Mawatari and T. Fukuuchi et al., 2013. Simultaneous determination of nicotine and cotinine in serum using high-performance liquid chromatography with fluorometric detection and postcolumn UV-photoirradiation system. J. Chromatogr. B., 934: 41-45.

Yu, C.C. and Y.C. Chang, 2013. Enhancement of cancer stem-like and epithelial-mesenchymal transdifferentiation property in oral epithelial cells with long-term nicotine exposure: Reversal by targeting SNAIL. Toxicol. Applied Pharmacol., 266: 459-469.

Zhou, Y., H. Yu, L. Zhang, H. Xu and L. Wu et al., 2009. A new spectrofluorometric method for the determination of nicotine base on the inclusion interaction of methylene blue and cucurbit [7] uril. Microchim. Acta, 164: 63-68.

Zuo, Y., L. Zhang, J. Wu, J.W. Fritz and S. Medeiros et al., 2004. Ultrasonic extraction and capillary gas chromatography determination of nicotine in pharmaceutical formulations. Anal. Chim. Acta, 526: 35-39. 